\title{
Fulfilling the "missing link" between university and authentic workplace in teacher training
}

\author{
Ebru Zeynep Muğaloğlu and Zerrin Doğanca \\ Bogazici University, Istanbul, Turkey
}

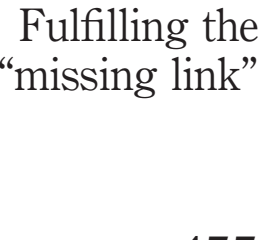

455

Received 10 October 2008

Revised 3 March 2009

Accepted 26 March 2009

\begin{abstract}
Purpose - This study aims to enable pre-service teachers to cooperate with teachers and to participate in solving classroom problems with the guidance of academic staff in an action research (AR) project.

Design/methodology/approach - Eight pre-service teachers took an AR course and simultaneously participated in a collaborative AR project. While learning about the steps and nature of AR, pre-service teachers worked with teachers and designed their own project proposals in order to solve classroom problems. A questionnaire about "doing" an AR and reports prepared by the pre-service teachers were used as instruments.

Findings - Pre-service teachers worked on different classroom problems together with the teachers and seven out of eight ARs were presented at a national teachers' conference. Moreover, all the pre-service teachers reported that they were eager to apply AR in their future classrooms and they decided to apply their AR proposals even though the course had finished.

Research limitations/implications - The study is limited by the participants and the instruments used here.

Practical implications - AR courses enable pre-service teachers to take an active role in authentic workplaces, thereby encouraging them towards workplace learning.

Originality/value - The study shows that collaborative AR can enable pre-service teachers to identify and solve classroom problems, thereby providing them with an environment in which to use their theoretical knowledge gained at university. Hence, AR courses could be integrated into teacher training programs in order to fulfil the missing link between theory and practice in teacher training.
\end{abstract}

Keywords Action research, Teachers, Workplace learning

Paper type Research paper

\section{Introduction}

Fulfilling "missing links" within teacher education programs is essential to improve the successes of these programs in terms of training highly qualified contemporary teachers who are expected to be collaborative, technology-literate and reflective practitioners as well as competent researchers. In this respect, the "theory-practice link between school and universities" is considered one of the keystones of a "coherent conceptual framework for teacher education programs" (Hoban, 2005). However,

The authors would like to thank the pre-service teachers and teachers who participated in the project and made invaluable contributions. It was a great pleasure to work with such a supporting and well-motivated team.

This study was supported by Bogazici University Scientific Research Projects Commission, which enabled the provision of the materials, instruments and service required by the study. Project no: 07HD101. Project date: 2007-2009.

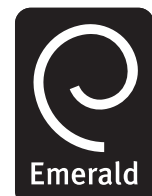

Journal of Workplace Learning Vol. 21 No. 6, 2009 pp. $455-464$

(C) Emerald Group Publishing Limited 1366-5626 DOI 10.1108/13665620910976739 
JWL 21,6 "discontinuities between university courses and school practices" exist, and these discontinuities are regarded as one of the problems of teacher education (Tom, 1997). According to Elliot (2001), the main reason of the theory-practice problem is that teachers often feel threatened by the "theory". Most of pre-service teachers and teachers argue that educational theories are not applicable in real settings. According to the conventional approach, universities present educational theories and schools are places to apply them. However, it is a common problem that teachers in classes do not incorporate their practices with theories studied previously at universities.

To combine theory and practice, linking ongoing school practices with the present coursework of pre-service teachers is recommended (Freese, 2005). In other words, a reform movement in teacher education is suggested to strengthen the bridge between schools and universities with the aim of pre-service teachers putting theories into action. Thus, workplace and college learning, which are similar in many respects, could be integrated (Hodkinson, 2005; Maaranen et al., 2008). It is also suggested that any reform should be inquiry-based, learner-focused and field-oriented (Phelan, 2005). In this respect, a possible solution could be conducting action research (AR) in collaboration with university faculty, pre-service teachers and in-service teachers in order to complete the missing link.

Concisely, AR is classroom-based research activities. It is empowered by the assumption that social change is possible through practitioner research. It involves a reflective process aiming at the professional development of an individual (Doerr and Tinto, 2000). So, the role of teachers shifts from a passive object (outsider) to an active participant (insider) in the research process. This active role involves determining the research question, hypothesising, collecting and interpreting data and communicating results. As opposed to the conventional view, in action research, both pre-service teachers and teachers generate knowledge from their own experiences (Hoban, 2005; Doerr and Tinto, 2000). In other words, action researchers, teachers or pre-service teachers "can and do construct knowledge about teaching, learning and schooling" (Doerr and Tinto, 2000). In this respect, AR is a powerful means to integrate theory into practice through inquiry and fieldwork.

On the other hand, the emphasis in AR movement is not the production of knowledge. AR is widely accepted as a means of simultaneously improving both pre-service teacher training and in-service professional development programs (Catelli, 1995). Moreover, to make academic research relevant, researchers have opportunities to try out their theories with practitioners in real situations and real organisations (Avison et al., 1999).

Within this framework, the present study aimed to assist pre-service teachers to combine pedagogical theories with the real-life situations in classroom settings by conducting a collaborative action research (CAR). Capobianco and Feldman (2006) stated that a "CAR group must function as both a community of practice and an epistemic community if both practice is to be improved and knowledge and understanding is to be generated". In order to construct a CAR group, eight voluntary pre-service teachers were matched with eight voluntary in-service teachers to conduct their own AR designs under the supervision of a faculty member. Therefore, each AR in this study can be considered as a "CAR" because three parties of education, including faculty members, in-service teachers and pre-service teachers, actively 
participated in each AR to understand teaching and learning processes (Levin and Rock, 2003).

As emphasized by Kitchen and Stevens (2008), the context was crucial in conducting an effective AR. The collaborative team in this study had a common belief in the main assumption of social change theory. Specifically, it was believed that little actions in class could create a change in learning environments in a positive way. The team members were well motivated to search for these little possible actions that would be crucial for the selected problems and conditions. Moreover, the team members were ready to support and learn from each other. In other words, in-service teachers, who had workplace experience, were familiar with the problems and the social context, whereas they were lacking new pedagogical approaches. On the other hand, pre-service teachers, who were lacking experience in terms of workplace learning, were open to learn new things about teaching, learning and the learning environment from their experiences of a real setting. The faculty member supported their systematic approach while designing and implementing an action research project, thereby integrating workplace and university learning.

The collaborative action research project (CARP) undertaken started with opening an elective AR course for pre-service teachers in the team. The course was given by the university supervisor of the CARP and aimed at empowering pre-service teachers with the necessary theoretical background and skills to design and apply action research. Within this framework, pre-service teachers were responsible for writing reflection papers throughout the term and an AR proposal. They prepared presentations about their own projects and shared them with their classmates and the eight experienced teachers in the overall project. During the course, in addition to classroom observations, pre-service teachers discussed the problems of real classroom settings related to teaching and learning with the teacher under the supervision of the faculty member.

In Dick's (2006) review of action research between 2004 and 2006, he claimed that the style as well as the quality of action ARs varied. One of the important factors affecting the quality was the review of the literature undertaken while designing and implementing the AR. Therefore, in this research pre-service teachers were responsible for reviewing the related literature under the supervision of the faculty member. The pre-service teachers generated possible solutions based on the literature. At the end of the course, the pre-service teachers submitted their AR proposals and were ready to conduct their own AR projects with their experienced counterparts in schools.

\section{Methodology}

\subsection{Sample}

The sample for the study included eight voluntary pre-service science/math teachers who attended the Primary Science Education Program at a public university in Istanbul. Two of the pre-service teachers were male and six were females. Moreover, all the participants in the sample were senior students except one very well motivated junior student.

\subsection{Treatment}

A special topic course on AR was opened in the autumn of the 2007-2008 academic year at Bogazici University. Students on this course were expected to be familiar with
Fulfilling the "missing link"

457 
JWL 21,6 pedagogical theories, classroom management strategies, and learning approaches to study collaboratively with an experienced teacher in a classroom setting. For this reason, only senior pre-service teachers (except one very motivated junior student) from the Primary Education Department were accepted to attend the course. The course aimed to ensure that the pre-service teachers had the necessary theoretical background and skills to undertake an AR project.

With this aim, the course took 12 weeks and included four stages. In the first stage, the faculty members explained the aims of the CARP as well as the expectations of the pre-service teachers during the project. Then they introduced the nature and the processes of AR. Moreover, activities aiming at revealing the pre-service teachers' opinions about the characteristics of effective and ineffective teachers were conducted. In addition, an assignment was given about the image of teachers in society. Thus, the pre-service students had a chance to think about the characteristics of effective teachers and the expectations of teachers from society. In the light of these activities; the philosophy, aim and the general framework of AR were discussed.

At the second stage, the pre-service teachers made presentations and discussed each step of AR in detail in the light of a textbook. The chosen textbook of the course was McNiff and Whitehead's (2006) All You Need to Know about Action Research. The book was very useful in explaining the overall steps of action research and its philosophy to teachers who wanted to focus on their own practices. Moreover, AR examples, tips and warnings were presented based on the course textbook. Meanwhile, the eight pre-service teachers met up with the eight volunteer experienced teachers at two different primary public schools. Then, each pre-service teacher was matched with one of these experienced teachers to collaborate in their AR project.

At the third stage, a questionnaire in line with the general steps of AR was developed. This questionnaire was used by teachers and pre-service teachers as a guideline for designing and implementing a CARP. The questionnaire consisted of three parts. In the first part, they were asked to clarify the problem that they wanted to deal with. The second part aimed to develop a proposal to solve the problem. The last part was related to the outcomes of the research after the implementation. Details of the questionnaire are given in the Appendix.

While dealing with the first part of the questionnaire, the pre-service teachers performed classroom observations for at least one hour in order to be familiar with the learning environment. Then, the problems to be studied were determined together with the in-service teachers. During the course, the pre-service teachers discussed their research problems and possible solutions in the light of the second part of the questionnaire. The pre-service teachers were also responsible for justifications of their proposed solutions in the light of their literature review. These discussions allowed them to share their AR projects with their classmates and develop a deeper understanding about AR. Moreover, in these discussions they were exposed to different problems and various styles of $\mathrm{AR}$ and became familiar with their workplaces.

At the end, the pre-service teachers were supposed to submit a report about their finalised AR proposals. The name, grade level of the eight AR projects, research problems and coping strategies based on pedagogical theories are listed in Table I.

After approval of the proposals, pre-service and in-service teachers volunteered to implement their action research projects. They also completed the third part of the 


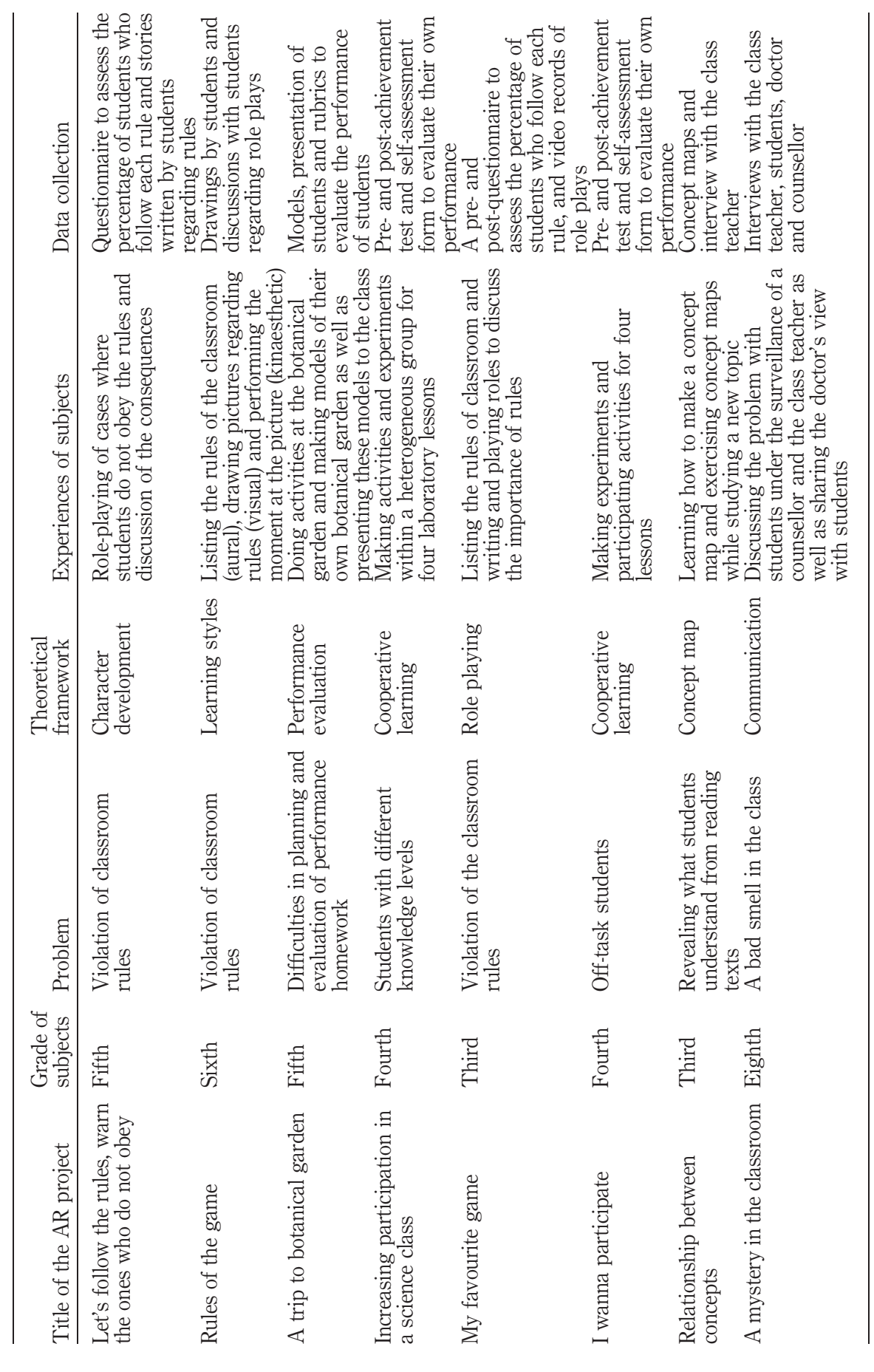

Fulfilling the
"missing link"

459

Table I.

Information about the $\mathrm{AR}$

projects 
JWL 21,6 questionnaire to discuss the outcomes of their projects. This step was out of the scope of this study and therefore the outcomes of each project are not included in this paper.

\subsection{Instruments}

The pre-service teachers were expected to submit a project report at the end of the term. The reports included:

- reflections about the course and what they learnt about AR;

- a course diary that included notes about what was done in each class;

- the timetable of the proposed AR project;

- reflections on classroom observations and meetings with teachers;

- theoretical frameworks of the problems and coping strategies;

- materials designed for the proposed projects (like role-playing texts, concept map samples, behavior questionnaires, etc.); and

- a plan for the steps to be followed in the following term.

In addition to these project reports, a questionnaire, which consisted of six open-ended questions, was prepared to reveal the pre-service teachers' views about the course and gains from the process of developing an action research proposal. The questions were related to:

- the reasons why they took the course;

- changes in their knowledge about the studied subject-matter;

- changes in attitudes towards the studied subject-matter;

- the relationship with the experienced teacher;

- whether they would recommend such a course to other pre-service teachers; and

- whether they would conduct an AR in future.

\section{Results}

Based on the reports and the responses to the questionnaire, it can be concluded that all of the pre-service teachers were glad to take the course and to participate actively in developing an AR proposal. Most of them stated that a contribution to their professional development was the main reason for taking an AR course. At the end of the course, the pre-service students expressed that:

- they actively participated in determining a real classroom problem and developing a solution for this problem within a theoretical framework;

- they enjoyed being part of a team as well as developing a sincere relationship between the team members;

- they did not waste their time;

- this experience contributed to their professional development; and

- they took responsibilities in a real educational setting.

However, one pre-service teacher also stated that taking responsibility was stressful. 
In this respect, all participants recommended other pre-service teachers to participate in such an AR course. All except one suggested that an action research course like this one should be a required course in teacher training programs. The one who suggested that the course be elective instead of required raised concerns about the quality of projects. He stated that the quality of the projects would be better if participation was voluntary.

Regarding the theory and practice link in developing solutions to real class problems:

- Six of the pre-service teachers stated that the theoretical framework which they chose and worked on was among the topics of their previous courses. Therefore, in this course, they had a chance to apply a theory with which they were already familiar, in a real classroom problem.

- On the other hand, two of the pre-service teachers chose theories that were not part of their previous coursework. However, one was very familiar with the issue due to her personal interest. The other pre-service teacher chose a topic with which she was not familiar. However, she explained that she realised the importance of the issue while observing the class, and therefore decided to put extra effort in to learn the theory.

- Five of the pre-service teachers stated that generating solutions in the light of related theory led to changes in their attitudes or/and knowledge levels.

Hence, it seemed that it was effective to encourage pre-service teachers to refer to the related theories in developing their project proposals.

Above all, all the pre-service teachers clearly stated that they would make use of AR steps to solve possible problems in their future classrooms. Moreover, two of them claimed that they had already adapted these steps to solve problems in their daily life. According to the participants, these steps helped them to be systematic, creative and organised.

Finally, as a concrete outcome of the study, it was observed that all of the pre-service teachers were eager to finalise their AR proposals even in the absence of any obligation to do so.

\section{Conclusion}

This study can be considered as an attempt to fulfil the missing link between theory and practice in teacher training. Based on the feedback from the participants, it can be said that they learned more about pedagogical theories while developing AR proposals collaboratively even if those theories were part of their previous courses. The pre-service teachers experienced a shift in status from being an intern to being a member of a research team. In this respect, they took responsibilities and actively participated in problem-solving processes. In other words, they did not only follow the guideline but also determined and shaped the research proposal in a practical working-life context. As Cornett (1990) assumes, they are expected to determine and shape the curriculum through AR when they become teachers.

However, the missing link between university and work life is a complex issue. As emphasised by Saarnivaara and Sarja (2007), knowledge, skills and competences do not guarantee a satisfactory transition from university to workplace life. Particularly, 
JWL 21,6 the new social context in the school environment makes this transition complicated for new teachers. During the formal education of pre-service teachers, taking responsibility, experiencing problems and working towards solutions in their future workplace might enhance their readiness for their new social context, namely the school environment. As stated by Etalapelto and Saarinen (2006), having the possibility of an active participatory role is crucial for the professional development of pre-service teachers. In the present study, CAR provided pre-service teachers with the possibility of an active participatory role because they had an opportunity to put their knowledge, competency and skills into practice in an authentic workplace. Within this framework, CAR in schools could be helpful in pre-service teachers' professional development as well as in making a successful transition from university life to working life.

In the literature, it is stated that the quality and success of CAR rely on forming a team that can act both as a community of practice and as an epistemic community. The basic dimensions of community of practice include mutual engagement, a joint enterprise and shared repertoire (Wenger, 1998). In the present study, in order to provide these dimensions, it was important to ensure that all the members participated voluntarily and were open to negotiation of meanings. In periodic meetings, which were open to all the team members, and during the discussions on the course, all kinds of contribution in pursuit of improvements in practice were welcomed and encouraged.

Regarding the epistemic community, researchers argue that the production of knowledge in AR is a side effect of improving practice (Lave and Wenger, 1991). However, the primary aim of the epistemic community is "to create and warrant knowledge" (Capobianco and Feldman, 2006). In this respect, the steps of AR must grounded on an appropriate research methodology. Therefore, in the present study, critical issues for designing research, such as sampling, validity, reliability and limitations of the proposed solutions, including the instruments to gather data, were also presented and discussed for each AR proposal in the light of McNiff and Whitehead's (2006) textbook.

Furthermore, in order to support production and dissemination of knowledge, team members were encouraged to share their workplace learning experiences in an academic environment. As a result, seven of the action researches have recently been presented at a national teachers' conference, which, we believe, is a crucial solid outcome of the project in pursuit of being a part of the "epistemic community".

Finally, this paper has focused on the benefits of the CARP to pre-service teachers. Therefore, learning outcomes related to teachers were not evaluated. However, at the end of the project, all of the in-service teachers who participated in this study stated that they looked forward to continuing with new AR projects. This observation supports that teachers are open to workplace learning. Therefore, it is suggested that further studies are carried out in order to examine the effectiveness of CAR on the workplace learning of both novice and expert teachers.

\section{References}

Avison, D., Lau, F., Myers, M. and Nielsen, P.A. (1999), “Action research”, Communications of the ACM, Vol. 42, pp. 94-7. 
Capobianco, B.M. and Feldman, A. (2006), "Promoting quality for teacher action research: lessons learned from science teachers' action research", Educational Action Research, Vol. 14 No. 4, pp. 497-512.

Catelli, L.A. (1995), "Action research and collaborative inquiry in school-university partnership", Action in Teacher Education, Vol. 26, pp. 25-38.

Cornett, J.W. (1990), "Utilizing action research in graduate curriculum courses", Theory into Practice, Vol. 29, pp. 185-95.

Dick, B. (2006), “Action research literature 2004-2006: themes and trends", Action Research, Vol. 4, pp. 439-58.

Doerr, H.M. and Tinto, P.P. (2000), "Paradigms for teacher centered, classroom-based research", in Kelly, A.E. and Lesh, R.A. (Eds), Handbook of Research Design in Mathematics and Science Education, Lawrence Erlbaum Associates, London, pp. 403-27.

Elliott, J. (2001), Action Research for Educational Change, Open University Press, Buckingham.

Etalapelto, A. and Saarinen, J. (2006), "Developing subjective identities", in Billett, S., Fenwick, T. and Somerville, M. (Eds), Work Subjectivity and Learning, Springer, Dordrecht, pp. 157-77.

Freese, A.R. (2005), "Innovation and change in teacher education: an inquiring, reflective, collaborative approach”, in Hoban, G.F. (Ed.), The Missing Links in Teacher Education Design: Developing a Multi-Linked Conceptual Framework, Springer, Dordrecht, pp. 117-34.

Hoban, G.F. (2005), The Missing Links in Teacher Education Design: Developing a Multi-Linked Conceptual Framework, Springer, Dordrecht.

Hodkinson, P. (2005), "Reconceptualising the relations between college-based and workplace learning”, Journal of Workplace Learning, Vol. 17 No. 8, pp. 521-32.

Kitchen, J. and Stevens, D. (2008), "Action research in teacher education: two teacher educators practice action research as they introduced action research to pre-service teachers", Action Research, Vol. 6, pp. 7-28.

Lave, J. and Wenger, E. (1991), Situated Learning; Legitimate Peripheral Participation, Cambridge University Press, Cambridge.

Levin, B.B. and Rock, T.C. (2003), "The effects of collaborative action research on pre-service and experienced teacher partners in professional development schools", Journal of Teacher Education, Vol. 54 No. 2, pp. 135-49.

Maaranen, K., Kynaslahti, H. and Krokfors, L. (2008), "Learning a teacher's work”, Journal of Workplace Learning, Vol. 20 No. 2, pp. 133-45.

McNiff, J. and Whitehead, J. (2006), All You Need to Know about Action Research, Sage Publications, London.

Phelan, A.M. (2005), "On discernment: the wisdom of practice and the practice of wisdom in teacher education", in Hoban, G.F. (Ed.), The Missing Links in Teacher Education Design: Developing a Multi-Linked Conceptual Framework, Springer, Dordrecht, pp. 57-73.

Saarnivaara, M. and Sarja, A. (2007), "From university to working life: mentoring as a pedagogical challenge", Journal of Workplace Learning, Vol. 19 No. 1, pp. 5-16.

Tom, A.R. (1997), Redesigning Teacher Education, State University of New York Press, Albany, NY.

Wenger, E. (1998), Communities of Practice: Learning, Meaning and Identity, Cambridge University Press, Cambridge. 
JWL 21,6

\title{
Appendix. Questionnaire for the CARP
}

\section{Part 1}

(1) What is the problem on which you want to work during the project?

(2) Why do you think that this problem is important?

(3) Would you please clarify the problem with an example from your class?

Part 2

(1) What are the possible solutions that you can think of? Make a literature review.

(2) Which one of the solutions is more plausible and applicable?

(3) How would you collect data (video recording, questionnaires, interviews, etc.)?

Part 3

(1) What are the impacts of the project on students? Justify your answer with data.

(2) What are the impacts of the project on your own understanding of learning and teaching?

\begin{abstract}
About the authors
Ebru Zeynep Muğaloğlu completed her $\mathrm{PhD}$ in the Science Education Department at Marmara University. Before her PhD studies between 2002 and 2006, she pursued an MA in the Philosophy program at the Institute of Social Sciences between 1997 and 2001 and a BS in the Chemistry Teaching program in the Department of Science Education at Bogazici University between 1991 and 1996. Dr Muğaloğlu has been an instructor at the Department of Primary Education at Bogazici University since January 2004. She lectured at the Secondary Science and Math Education Department of the same University between 2001 and 2004. Her research interests are radical constructivism in science education, epistemological positions for science teachers, pre-service teachers' views of the nature of science, action research projects and environmental education practices. Ebru Zeynep Muğaloğlu is the corresponding author and can be contacted at: akturkeb@boun.edu.tr

Zerrin Doğanca is a $\mathrm{PhD}$ student at the Institute of Environmental Sciences at Bogazici University. She has an MA degree in Environmental Sciences (2004-2007) and a BA degree in Primary Science and Mathematics from the Education Department at Bogazici University (1998-2003). After one year's teaching experience in a private primary school, she returned to the University and she has been a research assistant in Primary Education Department since 2005.
\end{abstract}

To purchase reprints of this article please e-mail: reprints@emeraldinsight.com Or visit our web site for further details: www.emeraldinsight.com/reprints 